\title{
Theory of Mind in Action: \\ Use of Mental State Understanding in Social Interactions
}

\author{
Uygulamalı Zihin Kuramı: Sosyal Iliş̧kilerde Başkalarının Düşüncelerini \\ Kavrama Becerisinin Kullanımı
}

\section{Ceymi DOENYAS *}

\begin{abstract}
Theory of mind (ToM) research mostly focuses upon the age at which children can pass laboratory ToM tasks, with less attention paid to how these acquired ToM abilities are actually used. We outline situational, social, and personal factors that may influence the deployment of ToM abilities in social settings. Although research on the social utilization of ToM is nascent, we wish to draw attention with this brief review to the need for, and the possibility of, a shift in focus in the field from the time of acquisition, to conditions helping or hampering the deployment of ToM in social contexts for children, as well as for adults. Such a perspective can help situate the extensive laboratory findings on ToM in reallife contexts and move closer to understanding the role of this socio-cognitive ability in actual social interactions, which is only natural given that ToM is considered as one of the foundations for social understanding.
\end{abstract}

Keywords: Mental State Understanding, Theory of Mind, Social, Interaction

Öz: Zihin kuramı araştırmaları çoğunlukla çocukların laboratuvar ortamlarında sunulan zihin kuramı görevlerini geçmeye başladıkları yaşın ne olduğuna odaklanır ve edinilen zihin kuramı becerilerinin gerçekte nasıl kullanıldığına daha az önem verir. Bu makalede, edinilen zihin kuramı becerilerinin sosyal ortamlarda uygulanmasını etkileyebilecek durumsal, sosyal ve kişisel faktörler incelenmiștir. Bu makale ile alanda zihin kuramının edinilme yaşından ziyade sosyal hayatta kullanımına yardımcı olan ya da engelleyen koşullara odaklanmanın, bu sosyal içerikli becerinin tanımına uygun bir şekilde incelenmesi için önemli olduğunu vurgulamak istemekteyiz. Çocuklar gibi yetişkinler için de bu becerinin edinilmiş olması, sosyal ortamlarda kullanılacağı anlamına gelmemekte ve yetişkinlerin zihin kuramı becerilerini hangi koşullarda daha fazla veya daha az kullanıldığının incelenmesi de önem taşımaktadır. Bu tür bir bakış açısı, zihin kuramı üzerine yapılmış kapsamlı laboratuvar bulgularını gerçek hayatın bağlamında yerleştirmeye yardımcı olabilir. Böylece, sosyo-bilişsel kabiliyetin gerçek sosyal etkileşimlerdeki rolünü anlamaya daha da yaklaşılabilir, ki bu da zihin kuramının sosyal anlayışın temellerinden biri olduğu düşünüldüğünde böyle bir yaklaşımın ne kadar gerekli olduğunun altını çizmektedir.

Anahtar sözcükler: Zihin Kuramı, Düşünce, Sosyal, İletişim

"When it comes to understanding others, we rarely tax our imaginations".

Lawrence Hill

Humans live and think socially, and human social cognition is largely believed to be based upon an understanding of ourselves and of others in terms of inner, mental, psychological states (Wellman 2014a). Theory of mind (ToM) refers to our understanding of the mental world; the

\footnotetext{
* PhD, Koç University Research Center for Translational Medicine, İstanbul, Turkey. ceymidoenyas@alumni. princeton.edu, https://orcid.org/0000-0002-4809-8719
} 
inner world of beliefs, desires, thoughts, perceptions, emotions, intentions, and other mental states (Flavell 2004). Developmental studies on ToM and related understandings have enjoyed great popularity over the last decades, and revealed certain age-related patterns of progression (Perner 1999; Wellman 2014b). The importance of interactions between the developing child and the social world has been acknowledged for the development of ToM, such as Nelson (2005) preferring "community of minds" instead of a theory of mind, emphasizing different interacting minds and the idea that theory of mind is a communally shared belief system about human goals, motivations, values, knowledge, and aspirations, and, Astington and Jenkins (1995) making the explicit effort to connect laboratory measures of ToM to children's behaviors in naturalistic settings and highlighting the two-way interaction between the child and the social world.

Yet, most research in this area has focused on an "understanding of theory of mind", with tasks developed and studies using them mainly being limited to the laboratory setting and investigating when children can pass them and be considered as having acquired that ToM understanding. Consequently, less attention has been given to the real-life usage of these acquired ToM abilities, and if, passing a ToM task in a laboratory setting actually corresponds to using it in social interactions, which is interesting, given the widely accepted belief in the literature that ToM and its development lie at the base of children's social understanding (Astington \& Edward 2010). Grueneisen, Wyman, and Tomasello (2015), who have conducted the only study so far that investigated the application of ToM skills in social interactions by children, point out the need for examining not just the presence/absence of socio-cognitive skills but also their application in social interactions. Thus, the present discourse looks at "ToM in action" [Talwar et al. (2007) refer to lying as "ToM in action"] and evaluates if individuals who have mastered certain ToM abilities reliably use them in social situations.

Given that adults can at times engage in automatic and seemingly effortless mental state attributions (Schneider et al. 2017), while at the same time children and adults who have mastered a ToM ability are observed, not to reliably use it in their social interactions, this discourse outlines the possible situational, social, and personal factors that may influence whether acquired ToM abilities are employed in social interactions or not.

\section{Acquisition vs. Deployment of ToM Abilities}

First-order ToM abilities, which refer to understanding the mental contents of another individual about an event in the world, develops around 3-5 years of age (Wellman et al. 2001), and second-order ToM abilities, referring to understanding an individual's belief about someone else's mental contents about an event in the world, develops around 6-8 years of age (Perner \& Wimmer 1985). Yet, there is a lag between the acquisition of these ToM abilities and their deployment in social contexts, such as 7-year-old children making moral judgments considering only first-order mental states, whereas 9- and 11-year-old children also making use of secondorder mental states when making moral judgments, suggesting a time lag between the understanding of second-order mental states and in using such understanding to make moral judgments (Hayashi 2007). Similarly, in a communication task where the limited perspective of the speaker had to be considered, 8-year-olds make more egocentric errors than 10-year-olds, suggesting that the ability to use others' perspective in communication has a longer developmental course than the acquisition of ToM skills that occurs by age 4-5 (Wang et al. 2016). However, the longer developmental course of the ability to use the acquired ToM abilities in social situations should not be interpreted to mean that after a certain point in development the fully developed mentalizing abilities are reliably used in social interactions.

Keysar, Lin, and Barr (2003) claim that although adults can reflectively use their false belief understanding, this ability is not integrated enough into the routine functioning of the 
interpretation system to enable spontaneous, non-reflective use, and adults do not reliably engage this ability in situations where it would be the most useful, namely when interpreting the actions of others. These authors show a dissociation in adulthood between the fully developed ToM abilities that enable reflectively reporting that the other person being interacted with is ignorant or has a false belief, and the reliable use of this ToM ability for the purpose it was designed for, to understand what the other person means. In a similar referential communication game, Dumontheil, Apperly, and Blakemore (2010) showed that a large proportion of participants from different age groups (7-9, 9-11, 11-13, 14-17, 19-27) frequently failed to take the director's perspective into account when interpreting his instructions, but there was an improvement in accuracy between 7-9 years to 14-17 years of age. Although from childhood to late adolescence there is improvement in using ToM in interpreting what others mean, deploying ToM in social interactions is still not automatic in adulthood.

Similar to the consideration in this paper of whether laboratory findings of ToM acquisition correspond to their utilization in social interactions, neuroimaging researchers have recently set out to devise more ecologically realistic tasks than earlier studies that required offline mentalizing (i.e., retrospectively interpreting an agent's behaviors) and did not include actual social interactions with another person with real outcomes (Gallagher et al. 2002; Rilling et al. 2004). These fMRI findings show activation of the recruited areas, and if ToM understanding is not engaged in these social interactions, there would not be ToM area activations in these studies. The most common brain areas associated with ToM are the medial prefrontal cortex, especially the anterior paracingulate cortex, and the posterior part of the STS at the temporoparietal junction. Both cooperative (trust game; McCabe et al. 2001) and competitive (rock, paper, scissors; Gallagher et al. 2002) two-person exchange games revealed activation in the anterior paracingulate cortex, an area that has been associated with mentalizing. However, although these studies found activations in the anterior paracingulate cortex, only Rilling et al. (2004) found temporal activations, and, in addition, showed activation in certain brain areas that may be involved in real world interactions and may not have been detected by offline mentalizing without real time social interaction. In Rilling et al. (2004)'s study, both areas mainly associated with the mentalizing network are activated, but methodologically they determined average contrast values for the group as a whole, so their findings should not be interpreted to mean that all participants in their study engaged both regions of the mentalizing network in all interpersonal interaction trials.

In some cooperative and competitive games, even though it may be logical to deploy ToM understanding, the full ToM network may not be engaged, as seen in the absence of temporal activations in McCabe et al. (2001) and Gallagher et al. (2002), and the behavioral findings of Keysar et al. (2003). Interestingly, the temporal activations that were absent in these studies were found when participants interpreted social exchange rules (Ermer et al. 2006), but this study failed to find the prefrontal activations associated with ToM, suggesting that different components of mentalizing tasks may cue the engagement of different ToM components. So, although the new approach of imaging while the participants are actually engaging in social interactions is more accurate in revealing the brain regions involved in real-life mentalizing, it should be kept in mind that such regions may not always be recruited in real-life social interactions, where even adults do not consistently engage their fully developed mentalizing skills.

Mentalizing abilities have also been commonly referred to as "folk psychology", which is a commonsense theory of mind about beliefs, desires, and other intentional states, whose function is to predict and explain human behavior and enable smooth functioning of interpersonal interactions (Stich \& Ravenscroft 1994). Given that such abilities are so commonly used in our daily lives and are posited to assist social communication, it is interesting that existing research 
on ToM has not given more attention to its utilization in social interactions, which is undertaken in the present discourse in the hope of initiating a focus shift in future studies on ToM. Though social understanding i.e. ToM and social competence have been differentiated (Bosacki \& Astington 1999), it seems that the distinction of acquisition vs. deployment of ToM abilities has not yet been given enough attention in the literature, which the present discourse aims to instigate.

\section{Situational Factors}

Situational factors that influence ToM deployment may pertain to complexity and cues indicating the usefulness of engaging ToM abilities. Language complexity seems to be a factor influencing the use of perspective information in social interactions for older children who have mastered ToM abilities (Wang et al. 2016), suggesting that the complexity of the language used or the complexity of other situational factors involved in social interactions may affect the deployment of ToM abilities in social exchanges. This agrees with the proposition by Samson and Apperly (2010) that what makes ToM hard for adults is the need to resist interference from their own egocentric perspective and the need to select, monitor, and integrate relevant situational cues to reason about others' mental contents. Thus, it seems that the more complex the situational factors are, the harder it is for children and adults to put their mentalizing abilities to action. Another possible situational factor comprises contextual cues indicating the utility of ToM engagement. Both children (Perner \& Wimmer 1985) and adults (Meijering et al. 2011) perform better in ToM tasks and strategic games respectively when they are cued to mentalize and reason about the mental state of others. This cueing factor might explain the link between reading fiction and better performance in ToM tasks that has been interpreted as reading literary fiction temporarily enhancing ToM (Kidd \& Castano 2013), an effect that has been extended to watching TV dramas, which also led to higher performance in ToM tasks (Black \& Barnes 2015). These findings may be also explained as fiction providing the necessary prompts about the utility of reasoning about mental states when understanding the storyline, which may then facilitate performance in following ToM tasks that require just that kind of cognitive reasoning. Grueneisen et al. (2015) found that children can use $1^{\text {st }}$ and $2^{\text {nd }}$ order belief reasoning to coordinate with peers to get a reward, but these children were also cued with leading questions that would indicate the utility of engaging their ToM abilities, which again corroborates the present case for the scaffolding provided by situational cues to promote the engagement of acquired ToM abilities in social interactions by both children and adults.

\section{Social Factors}

Social factors influencing ToM deployment may include attitudinal elements. Children who have acquired false belief understanding are less likely to evaluate unequal allocations to outgroup children as okay (Mulvey et al. 2016), suggesting a link between the ability to mentalize and a decreased tendency to act discriminatively according to stereotypes. However, the reverse can also hold and individuals with high prejudice levels may be less likely to deploy their acquired ToM abilities in social interactions with individuals whom they are prejudiced against. This possibility is supported by recent evidence showing Turkish children to have more accurate mindreading for ingroup members compared to outgroup members, and prejudice and perceived threat predicting lower mindreading (Gönültaş et al. 2019 [in press]). Additionally, though not ToM per se, adults simulate the actions of their ingroups in their motor cortex but do not simulate the actions of outgroups that are prejudiced against and disliked (Gutsell \& Inzlicht 2010), showing differential brain engagement for ingroups and outgroups. Interestingly, older children show less in-group favoritism bias than younger children, suggesting that some prejudicial factors may be overcome with age (Jordan et al. 2014), while it is yet to be 
elucidated if such an overcoming is related to the effortful engagement of ToM abilities in social situations to curb prejudicial attitudes. Given that the concept of "folk psychology" and mentalizing are common parts of our daily social lives, and that such relations between prejudice and mentalizing emerge in fields other than psychology that pertain to human thinking, such as literature, such as Mrs. Ackroyd from Agatha Christie's (1926) novel remarked, “...because it's so difficult for a foreigner to see our point of view” (p.167), it is somewhat unexpected that these topics are only recently being picked up by the psychological sciences. Such ideas about the greatness of the differences between the thinking style of oneself and the outgroup may discourage the effortful engagement of mentalizing abilities when interacting with individuals from one's outgroup, due to the belief that any attempt to mind-read would mostly be futile given the dissimilarities between the mental processing of the two groups.

\section{Personal Factors}

Personal factors that may influence ToM deployment in social interactions include motivation, mood, and physiological state. Carpenter, Green, and Vacharkulksemsuk (2016) recently proposed an individual difference in willingness to effort-fully engage with others' mental states which they termed "mind-reading motivation (MRM)". They showed this personal trait of MRM to be stable over time and to be different from ToM ability, aligning with the present suggestion that having acquired a ToM ability does not always correspond to its reliable deployment in social settings. Another factor that influences the effortful engagement of ToM abilities seems to be mood. Adults who felt sad were more likely to use their knowledge about others to make inferences about their mental states, compared to those who were happy, which the authors explain as sadness being linked to more systematic and deliberate processing (Converse et al. 2008). Additionally, the neuropeptide oxytocin that is associated with social behaviors is shown to improve the performance in inferring others' mental states from their eyes (Domes et al. 2007). Thus, the motivation to mind-read that may be stable over time while temporally unstable mood and hormonal changes may influence if individuals are likely or motivated to deploy their ToM abilities in social interactions.

\section{Conclusion}

Qualities of the social interaction context such as the complexity of the language used or other situational factors and cues indicating the utility of engaging mentalizing skills; social factors related to the qualities of the person being interacted with; and personal factors such as stable mentalizing motivation or mercurial mood and hormonal changes, may influence whether individuals are willing or motivated to put their acquired ToM abilities into action in their social interactions.

Age-related improvements are observed in children's ability to use ToM in social situations such as communication games (Dumontheil et al. 2010; Wang et al. 2016) and in consistently maintaining their lies (Talwar et al. 2007). Though adults are faster in correcting their egocentric errors than children (Epley et al. 2004), both children and adults are nonetheless prone to such errors, which may indicate either that automatic belief attributions do not necessarily mean accurate belief attributions, or, that the accurate automatic belief attributions are not utilized quickly enough to overcome egocentric biases in fast-moving social exchanges. In either case, some ToM deployments seem to be effortful and to require the active engagement of cognitive resources regardless of age.

There may exist both automatic ToM processes that operate unconsciously and unintentionally, alongside deliberate ToM processes that are always intentional and conscious (Schneider et al., 
2017) and future studies investigating automaticity of ToM in children and factors that hinder or foster ToM engagement in social contexts for children and adults can elucidate which conditions influence the deployment of automatic and deliberate ToM abilities and to what degree. Such findings will have the merit of not only helping situate ToM studies in real-life contexts but also of contributing to the current debates for the conceptualization of ToM as a unitary or dual system.

In conclusion, such investigations into when acquired ToM abilities are utilized or are not in real-life contexts can help produce more comprehensive conceptualizations of the theory of mind, which may follow to some extent the theory of thinking advanced by Perkins, Jay, and Tishman (1993) that goes beyond ability, and takes into consideration the dispositions of individuals with a triadic conceptualization comprising motivations, sensitivity to occasion referring to one's alertness to occasions that require certain thinking patterns, and ability. Similarly, it may be beneficial to take such a perspective for ToM in the literature and so to distinguish the ability to mentalize, the inclination/motivation to use it, and the various factors that modulate such motivations in individuals engaging in mental state attributions. 


\section{REFERENCES}

Astington J. W. \& Edward M. J. (2010). “The Development of Theory of Mind in Early Childhood”. Social Cognition in Infancy 5 (2010) 16-27.

Black J. \& Barnes J. L. (2015). "Fiction and Social Cognition: The Effect of Viewing Award-Winning Television Dramas on Theory of Mind”. Psychology of Aesthetics, Creativity, and the Arts 9 (2015) 423-429.

Bosacki S. \& Astington J. W. (1999). "Theory of Mind in Preadolescence: Relations Between Social Understanding and Social Competence”. Social Development 8 (1999) 237-255.

Carpenter J. M., Green M. C. \& Vacharkulksemsuk T. (2016). "Beyond Perspective-Taking: MindReading Motivation”. Motivation and Emotion 40 (2016) 358-374.

Christie A. (1926). The Murder of Roger Ackroyd. London 1926.

Converse B. A., Lin S., Keysar B. \& Epley N. (2008). "In the Mood to Get Over Yourself: Mood Affects Theory-of-Mind Use”. Emotion 8 (2008) 725-730.

Domes G., Heinrichs M., Michel A., Berger C. \& Herpertz S. C. (2007). "Oxytocin Improves "MindReading” in Humans”. Biological Psychiatry 61 (2007) 731-733.

Dumontheil I., Apperly I. A. \& Blakemore S. J. (2010). "Online Usage of Theory of Mind Continues to Develop in Late Adolescence”. Developmental Science 13 (2010) 331-338.

Epley N., Morewedge C. K. \& Keysar B. (2004). "Perspective Taking in Children and Adults: Equivalent Egocentrism But Differential Correction”. Journal of Experimental Social Psychology 40 (2004) 760768.

Ermer E., Guerin S. A., Cosmides L., Tooby J. \& Miller M. B. (2006). "Theory of Mind Broad and Narrow: Reasoning About Social Exchange Engages ToM Areas, Precautionary Reasoning Does Not”. Social Neuroscience 1 (2006) 196-219.

Flavell J. H. (2004). “Theory-of-Mind Development: Retrospect and Prospect”. Merrill-Palmer Quarterly 50 (2004) 274-290.

Gallagher H. L., Jack A. I., Roepstorff A. \& Frith C. D. (2002). "Imaging the Intentional Stance in a Competitive Game”. Neuroimage 16 (2002) 814-821.

Gönültaş S., Selçuk B., Slaughter V., Hunter J. \& Ruffman T. (2019 [in press]). "The Capricious Nature of Theory of Mind: Does Mental State Understanding Depend on the Characteristics of the Target?”. Child Development, Early Online View (2019) [in press].

Grueneisen S., Wyman E. \& Tomasello M. (2015). “'I Know You Don't Know I Know...' Children Use Second-Order False-Belief Reasoning for Peer Coordination”. Child Development 86 (2015) 287-293.

Gutsell J. N. \& Inzlicht M. (2010). "Empathy Constrained: Prejudice Predicts Reduced Mental Simulation of Actions During Observation of Outgroups”. Journal of Experimental Social Psychology 46 (2010) 841-845.

Hayashi H. (2007). "Children's Moral Judgments of Commission and Omission Based on Their Understanding of Second-Order Mental States”. Japanese Psychological Research 49 (2007) 261-274.

Jordan J. J., McAuliffe K. \& Warneken F. (2014). "Development of In-Group Favoritism in Children’s Third-Party Punishment of Selfishness". Proceedings of the National Academy of Sciences 111 (2014) 12710-12715.

Keysar B., Lin S. \& Barr D. J. (2003). "Limits on Theory of Mind Use in Adults”. Cognition 89 (2003) 25-41.

Kidd D. C. \& Castano E. (2013). "Reading Literary Fiction Improves Theory of Mind”. Science 342/6156 (2013) 377-380.

McCabe K., Houser D., Ryan L., Smith V. \& Trouard T. (2001). "A Functional Imaging Study of Cooperation in Two-Person Reciprocal Exchange". Proceedings of the National Academy of Sciences 98 (2001) 11832-11835.

Meijering B., van Rijn H., Taatgen N. \& Verbrugge R. (2011). "I Do Know What You Think I Think: Second-Order Theory of Mind in Strategic Games is Not That Difficult". Proceedings of the $33^{\text {rd }}$ Annual Conference of the Cognitive Science Society (2011) 2486-2491. 
Mulvey K. L., Buchheister K. \& McGrath K. (2016). "Evaluations of Intergroup Resource Allocations: The Role of Theory of Mind”. Journal of Experimental Child Psychology 142 (2016) 203-211.

Perkins D. N., Jay E. \& Tishman S. (1993). "Beyond Abilities: A Dispositional Theory of Thinking”. Merrill-Palmer Quarterly (1982-) (1993) 1-21.

Perner J. \& Wimmer H. (1985). “'John Thinks That Mary Thinks That...’ Attribution of Second-Order Beliefs by 5- to 10-Year-Old Children”. Journal of Experimental Child Psychology 39 (1985) 437471.

Perner J. (1999). “Theory of Mind”. Developmental Psychology: Achievements \& Prospects (1999) 205-230.

Rilling J. K., Sanfey A. G., Aronson J. A., Nystrom L. E. \& Cohen J. D. (2004). "The Neural Correlates of Theory of Mind Within Interpersonal Interactions”. Neuroimage 22 (2004) 1694-1703.

Samson D. \& Apperly I. A. (2010). "There is More to Mind Reading Than Having Theory of Mind Concepts: New Directions in Theory of Mind Research”. Infant and Child Development 19 (2010) 443-454.

Schneider D., Slaughter V. P. \& Dux P. E. (2017). "Current Evidence for Automatic Theory of Mind Processing in Adults”. Cognition 162 (2017) 27-31.

Stich S. \& Ravenscroft I. (1994). “What is Folk Psychology?”. Cognition 50 (1994) 447-468.

Talwar V., Gordon H. M. \& Lee K. (2007). "Lying in the Elementary School Years: Verbal Deception and its Relation to Second-Order Belief Understanding”. Developmental Psychology 43 (2007) 804810.

Wang J. J., Ali M., Frisson S. \& Apperly I. A. (2016). "Language Complexity Modulates 8-and 10-YearOlds' Success at Using Their Theory of Mind Abilities in a Communication Task”. Journal of Experimental Child Psychology 149 (2016) 62-71.

Wellman H. M. (2014a). "Theory of Mind, Development, and Foundational Human Cognition”. Making Minds: How Theory of Mind Develops (2014). New York.

Wellman H. M. (2014b). "Extended Progressions in Theory-of-Mind Understanding”. Making Minds: How Theory of Mind Develops (2014). New York.

Wellman H. M., Cross D. \& Watson J. (2001). "Meta-Analysis of Theory-of-Mind Development: The Truth About False Belief”. Child Development 72 (2001) 655-684. 